\title{
Comparative Efficacy of Ovsynch and Double PG Protocols in Postpartum Anoestrus Graded Murrah Buffaloes (Bubalus bubalis)
}

\author{
B. Chandra Prasad , M. Srinivas, K. Sadasiva Rao
}

Department of Veterinary Gynaecology and Obstetrics, NTRCVSc, Gannavaram, Sri Venkateswara Veterinary University, Tirupati

*Corresponding author Email:cpmail@rediffmail.com,09490724881

Journal of Livestock Science (ISSN online 2277-6214) 10: 6-8

Received on 18/11/2018; Accepted on 11/1/2019

doi. 10.33259/JLivestSci.2019.6-8

\begin{abstract}
This study was conducted to evaluate the efficacy of Ovsynch and double PG protocols in postpartum anoestrous Graded Murrah buffaloes during the period October 2017 to December 2017. Based on history and per rectal palpation twice at ten days interval 30 postpartum anoestrous buffaloes were selected to induce estrus using Ovsynch and double PG protocols. These selected animals were randomly divided into three groups: Group I: Ovsynch protocol $(n=10)$ having smooth ovaries, Group II: Double PG protocol $(n=10)$ the animals that are cyclical and subestrus, Group III control $(n=10)$ normal cyclic without any hormonal intervention. All the animals were initially dewormed with oxyclozonide and supplemented with mineral mixture. Before initiation of treatment, blood samples were collected for estimation of serum calcium and phosphorus. In Group III animals estrous response was recorded as $60 \%$. Conception rate was higher in Group I (60\%) than in Group II (50\%) and Group III $(33 \%)$. Furthermore, no significant difference was recorded in the levels of serum calcium and phosphorus in between the groups.
\end{abstract}

Keywords: Buffalo; Double PG; Ovsynch; Postpartum anoestrous 


\section{Introduction}

Dairying is the integral part of agriculture and contributed significantly to the GDP of the country. Breeding of buffaloes throughout the year plays a vital role for maintaining dairy as profitable unit. Inherent reproductive problems exist in buffaloes like, delayed puberty, higher age at first calving, postpartum anoestrous, silent heat, seasonality in breeding and low conception rate Terzano et al.,(2012). Postpartum anoestrous in buffaloes is the most prevalent, frustrating and challenging problem encountered by the field veterinarians, which is major constraint that inhibited that reproductive potential at field level Das and Khan, (2010).

Lower levels of nutrients like, macro and micro-minerals are found to be involved in various types of anoestrous in buffaloes Abou-Zeina et al., (2009). Reproductive problems may be precipitated by deficiency of single or combined trace elements and by their imbalances in rations. Alterations in the Luteinizing hormone (LH) pulsality culminated to prolonged postpartum anoestrous Kumar et al, (2010). Butani et al., (2009) opined that prostaglandin based hormonal protocols had improved the conception rate at an induced estrus.

The present study was designed to compare the efficacy of Ovsynch and Double PG protocols in postpartum anoestrous Graded Murrah buffaloes.

\section{Materials and Methods}

The present study was conducted on postpartum Graded Murrah buffaloes located in and around Gannavarm, Andhra Pradesh during the period October 2017 to December 2017.The animals were fed with green fodder, dry hay and concentrate regularly.

The study comprised of 30 postpartum anoestrous buffaloes $\left(2^{\text {nd }}\right.$ to $5^{\text {th }}$ parity) that were selected based on history, per-rectal examination and by ultrasonography twice at 10 day interval. Anoestrous buffaloes ranged between 60-90 days postpartum are selected and randomly divided into three groups based upon their ovarian status.

Group I animals $(\mathrm{n}=10)$ having smooth ovaries were subjected to ovsynch protocol, Group II animals ( $\mathrm{n}=10$ ) that are cyclical and sub-estrus (that have not shown estrus symptoms) were subjected to double Prostaglandin protocol and Group III animals $(n=10)$ normally cyclic kept as control while day of start of treatment was considered day 0 for all the three groups.

Blood sample was collected with aseptic procedure by jugular vein puncture from each buffalo in a clot activation vacutainer on day 0 of treatment in each group. The blood samples were centrifuged at $3000 \mathrm{rpm}$ for 15 minutes to separate serum for estimation of calcium and phosphorus.

\section{Hormone treatment protocol}

Group I animals were subjected to Ovsynch protocol i.e $10 \mu \mathrm{g}(2.5 \mathrm{ml})$ of GnRH analogue I.M. (Buserelin acetate) was administered on day 0 followed by an Intra Muscular injection of 500 $\mu g$ Prostaglandin $\mathrm{F}_{2} \alpha$ (Cloprostenol) on day 7. A second injection of $10 \mu \mathrm{g}$ of $\mathrm{GnRH}$ was administered on day 9. Fixed time artificial insemination was carried out $14 \pm 2$ hours after the second dose of GnRH. Group II animals were subjected to Double PG protocol i.e. buffaloes were administered I.M. injection of 500 $\mu \mathrm{g}$ Cloprostenol on day 0 of treatment. This was followed by a second injection with the same dose on 11 days after first injection of PGF $2 \alpha$. Fixed time artificial insemination was carried out $54 \pm 2$ hours after the second dose of cloprostenol. Group III animals were observed for estrus without any hormonal intervention.

Estrus was confirmed by behavioural signs and per rectal examination in Group III animals. Pregnancy diagnosis was carried out 60 days after artificial Insemination by transrectal ultrasonography. The serum calcium and phosphorus was estimated by using OCPC Method and Molybdate U.V method, respectively.

\section{Results}

Intensity of estrus signs was assessed by behavioural signs, physiological changes and by per-rectal examination. Estrus signs were observed in $60 \%(6 / 10)$ of buffaloes in Group III. Whereas conception rate in Group I, Group II and Group III was $60 \%(6 / 10)$, 50\% (5/10) and 33.3\% (2/6) animals respectively. No significant difference was recorded in the levels of serum calcium and phosphorus in between the groups.

The overall Mean serum Calcium levels at initiation of hormonal treatment was $8.71 \pm 0.12$ (7.9 to 9.7) in Ovsynch group, $9.03 \pm 0.29$ (8.6 to 9.7) in double PG group and $8.91 \pm 0.22$ in control, respectively. Whereas phosphorus levels were recorded as $5.38 \pm 0.25$ in ovsynch, 5.46 \pm 0.12 in double PG group and 5.35 \pm 0.28 in control respectively. 


\section{Discussion}

Gonadotropin releasing hormone (GnRH), prostaglandins (PGF2 $\alpha$ ) and their different synthetic analogues have been used for estrus synchronization in cattle buffaloes in low breeding season under field conditions.(Khumran et al., 2012).

Estrus induction rate in Group I and II was higher in our study, when compared to other studies (Bhoraniya et al., 2012; Ali et al., 2012) in buffaloes which might be due to differences in feeding and frequency of observation with regards heat detection.

There was no significant difference in the level of calcium and phosphorus between the both groups and non significant variation was recorded between conceived and non-conceived buffaloes. Savalia et al. (2013) reported similar findings in postpartum anoestrous buffaloes treated with Ovsynch protocol.

Ovsynch treatment has been successfully used in swamp buffaloes for improved ovulation with acceptable fertility rates, Chaikhun et al., (2010). It reduced the incidence of anestrous in Murrah buffalo from $45 \%$ before treatment to $18 \%$ after treatment Roy and Prakash, (2009). Similarly, conception rate was more in Ovsynch group (50\%) than Double PG group (33.3\%) in the present study. Conception rate following Ovsynch protocol was achieved higher in acyclic cows (9\%) and buffaloes (0-7\%) following Ovsynch protocol (Azawi et al., 2012). Ahlawat et.al.(2015) reported a higher conception rate of $66.6 \%$ in Jaffarabadi buffaloes that were treated with double PGF2 $\alpha$.

It is concluded from the present study the ovysnch was a better suited hormonal protocol for acyclic buffaloes while double prostaglandin is more suitable in sub-estrous buffaloes.

\section{References}

1) Abou-Zeina HAA, Hassan SG, Sabra HA, Hamam AM, 2009.Trials for elevating adverse effect of heat stress in buffaloes with emphasis on metabolic status and fertility. Global Veterinary Journal, 3: 51-62.

2) Ahlawat AR, Ghodasara SN, Dongre VB, Gajbhiye PU, Murthy KS, Savaliya KB,Vataliya PH.(2015).Estrus induction in Jaffarbadi buffaloes. The Asian Journal Of Animal Science 10( 1)pp: 54-57

3) Ali R, Shukla SP, Nema SP,2012. Hormonal induction of ovarian cyclicity and conception rate in postpartum anoestrous buffaloes, Indian Journal of Field Veterinarians, 7: 44-46.

4) Azawi OI, Ali MD, Oday SA, Al-Hadad AS, Mouayad SJ, Abdul Hussien AS,2012. Treatment of anoestrous in Iraqi buffaloes using Ovsynch alone or in combination with CIDR, Journal of Advanced Veterinary Research, 2: 68-72.

5) Bhoraniya HL, Arjunbhai J, Dhami AJ, Naikoo M, Parmar BC, Sarvaiya NP,2012. Effect of estrus synchronization protocols on plasma progesterone profile and fertility in postpartum anoestrous Kankrej cows, Tropical Animal Health and Production 44: 1191-1197.

6) Butani MG, Dhami AJ, Ramani VP, Savaliya FP, Patel MD,2009. Influence of hormonal and non-hormonal therapy on fertility and serum minerals profile of conceiving and non-conceiving anoestrus buffaloes. Indian Journal of Field Vetreinarian 5: 59-67

7) Chaikhun T, Tharasanit T, Rattanatep J, De Rensis F, Techakumphu M,2010. Fertility of swamp buffalo following the synchronization of ovulation by the administration sequential of GnRH and PGF2 $\alpha$ combined with fixed-timed artificial insemination. Theriogenology 74:1371-1376.

8) Das GK, Khan FA,2010. Summer anoestrous in buffalo-a review, Reproduction in Domestic Animals. 45: 483-494.

9) Khumran AM, Roshina Y, Ariff MO, Wahid H, Dhaliwala G, Khanh NP, Yap KC, Fahmi M, Azmil ME,2012. Comparison of estrus response and pregnancy rate of beef cows synchronized with Progesterone and prostaglandin based protocols. Journal of Animal and Veterinary Advances 11 (19): 3561-3567.

10) Kumar S, Saxena A,Ramsagar.2010. Comparative studies on metabolic profile of anoestrous and normal cyclic Murrah buffaloes, Buffalo Bulletin, 29: 1-4.

11) Roy KS, Prakash S. 2009. Changes in endocrine profile during Ovsynch and Ovsynch plus nor prolac treatment in Murrah buffalo heifers at hot summer season. Tropical Animal Health and Production 4: 677687.

12) Savalia KK, Dhami AJ, Patel KR,Hadiya K K. 2013. Influence of controlled breeding techniques on fertility and plasma macro-minerals profile in conceived and non-conceived anestrus and repeat breeding buffaloes. Indian Journal of Field Veterinarians 9: 28-35.

13) Terzano GM, Barile VL, Borghese A. 2012. Overview on reproductive endocrine aspects in buffalo. Journal of Buffalo Science 1: 126-138. 